\title{
The evaluation of quality in social-work practice
}

\section{Björn Blom}

Dept. of Social Work

Umeå University

Email: bjorn.blom@socw.umu.se

\section{Stefan Morén}

Dept. of Social Work

Umeå University

Email: stefan.moren@socw.umu.se

\begin{abstract}
This theoretical article describes and discusses the concept of quality in relation to the evaluation of social-work practice. Of particular interest are the difference between quality of services and quality of life and the importance of balancing the stakeholders' different interests in order to make a sound judgement of quality in social work possible. This article begins with presenting some basic perspectives on quality as well as the transference of the concept of quality from manufacturing industry to social-work practice. Thereafter the two main issues are discussed: the concepts of quality of service and of quality of life and the importance of balancing different stakeholders' perspectives in the evaluation of quality in social-work practice. This article concludes that: 1) it is crucial to be aware of and to consider the distinction between quality of service and quality of life; 2) clients' perspective on quality of life is an aspect of outcome that currently receives insufficient attention; 3) clients' subjective experiences of welfare or well-being deserve greater attention for ethical as well as methodological reasons; and 4) judgement of quality in social work are inevitably dependent on different stakeholders' perspectives.
\end{abstract}

Keywords: evaluation, quality of life, quality of service, welfare, well-being, social work 


\section{Why focus on quality of life in social-work practice?}

It is probably not controversial to claim that it is important to evaluate socialwork practice. It is also reasonable to assert, as Stake and Schwandt (2006) do, that evaluation to a great degree is concerned with discerning and substantiating quality. At a general level we can presume that most people would agree on this point, whether they are a politician, civil servant, researcher, social worker, client, taxpayer and so on. However, at a more concrete level - when it comes to the evaluation of specific activities - it can be far more difficult to reach a consensus about what should be evaluated and how an evaluation should be carried out. The authors of this article believe that one reason that makes it difficult to obtain unity about the evaluation of social-work practice is that there are a number of possible answers to a basic question: why does social work exist?

There are several ways to respond to this question and the conceptions can differ between individuals, organizations, countries, cultures, and more. Let us present a few examples. One answer might be that social work exists because people have material needs that must be met. Another answer might be that social work exists in order to get the 'societal machinery' to run smoothly by fixing the problems that 'disturbing' citizens create. In other words individuals with problems are to be (re)adapted to society. A third way of viewing this is that social work aims at developing and changing societies. Yet another answer is that the purpose of social work is to emancipate people from constraining forces and structures in society. In this article we argue that social work primarily exists in order to maintain a good quality of life or to improve the insufficient quality of life that socially vulnerable people might often face. This is a normative standpoint, which we believe has concrete consequences for evaluation of social-work practice. It directs a focus on quality of life as an important aspect of an outcome and it reminds us that the stakeholders' perspective is constantly present.

\section{The aim of the article}

This article discusses quality in relation to the evaluation of social-work practice. The aim is to highlight and to investigate two important aspects of this issue:

1) The difference between quality of services and quality of life: We especially point to the relevance of the latter in the context of social work.

2) The importance of balancing the stakeholders' different interests in order to make a sound judgement of quality in social work possible: In this act of balancing, we especially stress the relevance of the clients' perspective.

As the evaluator often has the most far-reaching possibility and responsibility of considering different aspects of quality within an evaluation, the issue of quality is primarily discussed from the evaluator's perspective. First we present, as a background to the discussion of the two main issues, some basic perspectives on quality as well as the transference of the concept of quality from manufacturing industry to social-work practice. One important aspect of this transference is the differences between quality of goods and 
quality of services. We shall thereafter address the first main issue and discuss the concepts of quality of service and quality of life in relation to social work. Two central aspects of quality of life are stressed, welfare and wellbeing. The discussion of the second main issue involves the delicate matter of balancing different stakeholders' perspectives in the evaluation of quality in social-work practice. We emphasize especially the importance of acknowledging the client as a stakeholder. Finally, the article ends with a brief concluding discussion.

To a large extent, this article draws from our own experiences of evaluating different social-work agencies (mostly municipal social services) in different parts of Sweden (e.g. Blom, 1996, 1998; Blom \& Morén, 2007; Morén, 1992, 1996; Morén \& Blom, 2003; Nordlander \& Blom, 2000). We have also developed a theory for evaluation of social-work practice, concentrating on the way social work is organized in the Nordic countries (Blom \& Morén, 2010, 2011, Morén \& Blom, 2003).

\section{Perspectives on quality}

The concept of quality stems from the Latin word qualitas, which means 'property' or 'characteristics'. The concept also implies an order of precedence, that is, the discerning of something that is considered to be good or desirable (Dahler-Larsen, 2008). In everyday life it is fairly self-evident and unproblematic to talk about different qualities of cars, clothes, furniture, and so on. These items are considered to have different characteristics that can be graded as better or worse. In contrast, when it comes to social work we have to consider immaterial and abstract entities like structure, process, and goalfulfilment. In the course of carrying out evaluations, we face the task of discerning, describing, and measuring qualities of these immaterial and abstract entities.

Discerning quality in social-work practice necessarily includes expectations and comparisons (Stake \& Schwandt, 2006). There is always someone (an individual, group or stakeholder) who has certain expectations concerning the quality that is to be judged. One cannot talk about quality (in a positive meaning) without involving comparisons, and sometimes even words that denote the lack of quality, like 'inferiority', 'meaninglessness', or 'worthlessness'. This means that quality is rarely unambiguous and is often disputable. As Stake and Schwandt note, 'Quality is multifaceted, contested, and never fully representable' (2006, p. 405). Consequently, perspectives, concepts, and theories are needed to help us to capture this elusive property.

Dahler-Larsen (2008) defines quality from five perspectives: 1) reducing variations around a defined standard, 2) obtaining certain effects, 3) reaching declared political goals, 4) meeting the preferences of the users, and 5) securing quality by the organizational system. These perspectives build on different problem areas as well as different criteria of quality.

1) Reducing variations around a defined standard. This perspective presumes that there is a certain quantitative or qualitative standard regarding what is considered to be an acceptable level of quality. For example, it can be about certain types of work tasks that are expected to be carried out within a stated time limit (quantitative), or about attaining in recurring surveys a certain level of reported client or customer satisfaction (qualitative). Thus, the criterion of 
quality in this perspective is about the work being as close as possible to a stated standard. However, there can be different sources that influence the formulation of these standards, like political agreements, managerial considerations or different stakeholders' preferences. Standardization sometimes serves as an effective guiding principle, but in a complex enterprise like social work there are many elements that are not possible to standardize. For example, the relationships and therapeutic alliances between social workers and their clients cannot be standardized. However there are a number of fundamental aspects of the relationships between social workers and clients that have shown to be relatively general and thus important to pay attention to when evaluating social-work practice. These are, for example, empathy, commitment, trust, caring, genuineness, and acceptance (Frank and Frank, 1991; Howe 1987, Knei-Paz, 2009; Miller \& Rollnick, 1991).

2) Obtaining certain effects. Public organizations are often described and valued on the basis of the resources they possess and the welfare services they deliver (i.e., outputs). A typical measure for these outputs would be, for instance, the number of treatment sessions or a certain number of residents in a home for geriatric care. It is equally important, however, to obtain knowledge on the effects of these interventions in people's lives (i.e., outcomes). ${ }^{1}$ Accordingly, the criterion of quality concentrates on the improvements that are achieved in people's lives and in society at large. This knowledge might be difficult to obtain, especially if one wants to know if the effects stem solely from interventions. In spite of the difficulties it is not impossible to obtain this kind of knowledge from an evaluation. In the field of Human Services, efforts are made to handle this problem from different methodological and metatheoretical perspectives, for example, by using experimental or quasiexperimental designs (Roberts \& Yeager, 2004) or a critical realist approach (Blom \& Morén, 2010; Kazi, 2003, Pawson \& Tilley, 1997).

3) Reaching declared political goals. Political decisions form the source of the overarching goals of public organizations. For social-services agencies and other similar agencies, a common point of departure for the evaluation of quality is the political goals on different levels in the so-called parliamentary chain of governance (see Vedung, 2009). Accordingly, the criterion of quality is about the extent to which political goals are obtained. A common problem with this perspective is that political goals are often stated in a generalized way, which makes them rather tricky to measure empirically. Further, especially in complex enterprises like social work, interventions may also cause side effects, both positive and negative, that are not present in the general political goals. An evaluator's concentrated focus on an organization's achievement of political goals (e.g., the implementation of a purchaserprovider split) could mean that unintended consequences (e.g., diminished cooperation between professional) go unnoticed.

4) Meeting the preferences of the users. In the same way that customer investigations are carried out in profit-based private enterprises, it is now almost standard procedure to ask for clients' or users' opinions on the interventions in public organizations. The users' opinions provide a criterion of quality and contribute to continuously developing the activity and in this way help to even out differences in power relations in society. However, in social

${ }^{1}$ The meaning of the concepts 'outputs' and 'outcomes' will be described below. 
work it is not always obvious who the users are. A certain type of intervention might focus on, say, vulnerable children or adolescents, but these may not be the only users; their parents, siblings, and grandparents may also be users. Sometimes information can be gathered indirectly by turning to different user organizations.

To secure quality by means of the organizational system. This perspective involves the idea that quality is a matter of controls that should be built into the organizational structure. This kind of 'quality assurance' often involves different documentation systems that ensure the continuous gathering of adequate data. Sometimes this kind of system is criticized for being too generalized and abstract and therefore unable to focus at the quality of client work itself.

These five perspectives provide a basis that takes us part of the way to understanding the meaning of quality. In the rest of the article, we shall discuss the concept of quality and the evaluation of quality, especially in relation to the area of social work.

\section{The issue of quality - from the manufacturing industry to social-work practice}

Somewhat surprisingly, many of the issues concerning quality in social-work practice come from the manufacturing industry. The focus on quality in the manufacture of goods was a way of reducing the amount of products that needed to be thrown away. In a free market it is important for the survival of a company that the quality of its products corresponds to the customers' expectations and willingness to pay. This means that the quality of a product is defined not only in relation to the product itself, but also to the customer's expectations concerning, for instance, the cost, appearance, reliability, performance, safety, and environmental influence. This way of reasoning about quality, which concerns material goods, spans from the purchase of a cup of coffee to the purchase of a car or an apartment, is for most people a natural part of everyday life.

This mindset was gradually transferred from the manufacturing industry and used as well in the service sector. The concept of quality came to include the production of physical goods and of services because of the need to compete in a market. Table 1 below shows a comparison between goods and services.

Even though social workers are not salesmen and clients are not customers, it is obvious that social work involves the production (or rather provision) of services. Let us imagine, for example, a woman who has contacted a social worker at a hospital in order to share her feelings after a miscarriage. This type of counselling means, by necessity, that the service is provided and consumed simultaneously in the encounter between these two persons. The service itself cannot be stored, but the experience of the service can linger on in the consciousness of these persons. Though services are delivered and consumed almost simultaneously, it is important to consider that necessary conditions for services already exist before the services are provided (e.g., social workers' education, organizations, resources, laws). This point implies that we must account for contextual factors if the ambition is to reach a more comprehensive understanding of how quality in social-work practice emerges. 
Table 1. Examples of differences between goods and services. Source: Sundström (2009:25, our adaptation).

\begin{tabular}{cc}
\hline Physical goods & Services \\
\hline A physical product & $\begin{array}{c}\text { Production and consumption are often } \\
\text { simultaneous }\end{array}$ \\
$\begin{array}{c}\text { The basic value is produced in a factory } \\
\text { or similar place of production }\end{array}$ & $\begin{array}{c}\text { The basic value is produced through the } \\
\text { interaction between customer and } \\
\text { provider }\end{array}$ \\
$\begin{array}{c}\text { The customers usually do not participate } \\
\text { in the process of production }\end{array}$ & $\begin{array}{c}\text { The customers participate in the process } \\
\text { of production }\end{array}$ \\
$\begin{array}{c}\text { Can be stored (with the provider as well } \\
\text { as the customer) }\end{array}$ & $\begin{array}{c}\text { Cannot be stored } \\
\text { Indirect contacts (e.g., through a retailer) } \\
\text { often possible }\end{array}$ \\
\end{tabular}

So far we have discussed the fundamental differences between goods and services and that quality not only relates to the inherent properties of the product or the service, but also to the experiences of the customer or client. The phrase 'the customer is always right' captures this idea in the business sector. The customers' attitudes and preferences serve as guidelines for the kinds of products or services that will be delivered - even if the customer's apprehensions do not correspond to the general (or societal) ideas concerning what is appropriate to demand. In social-work practice, depending on the character of the task, this matter is somewhat more complex. One major reason for this complexity is that the client does not have the sole prerogative to claim what good quality is. This is an issue about stakeholders' perspectives, which will be discussed in a later section, but first we shall focus on the difference between quality of service and quality of life.

\section{Quality of service and quality of life}

Different types of public organizations, such as the social services, the healthcare system, and schools, often carry out social work. Obviously, it is important that these organizations function as well as possible, that is, that they provide a good quality of service. This kind of quality refers to the resources and professional competences in the organization and the service that is provided. What is equally important is that these resources and services lead to the intended results, that is, improvements in the clients' life-situation, or, more succinctly, a good quality of life (or at least better than before). This kind of quality refers to life circumstances in general, as well as well-being. Osborne (1992) shows how the evaluation of social work not only demands a working knowledge of quality of service and quality of life, but also knowledge about the influences of context. Figure 1 below illustrates Osborne's view on quality in relation to the evaluation of human services. 
Figure 1. Production of human services and their links to quality of service and quality of life. (Osborne, 1992:447).

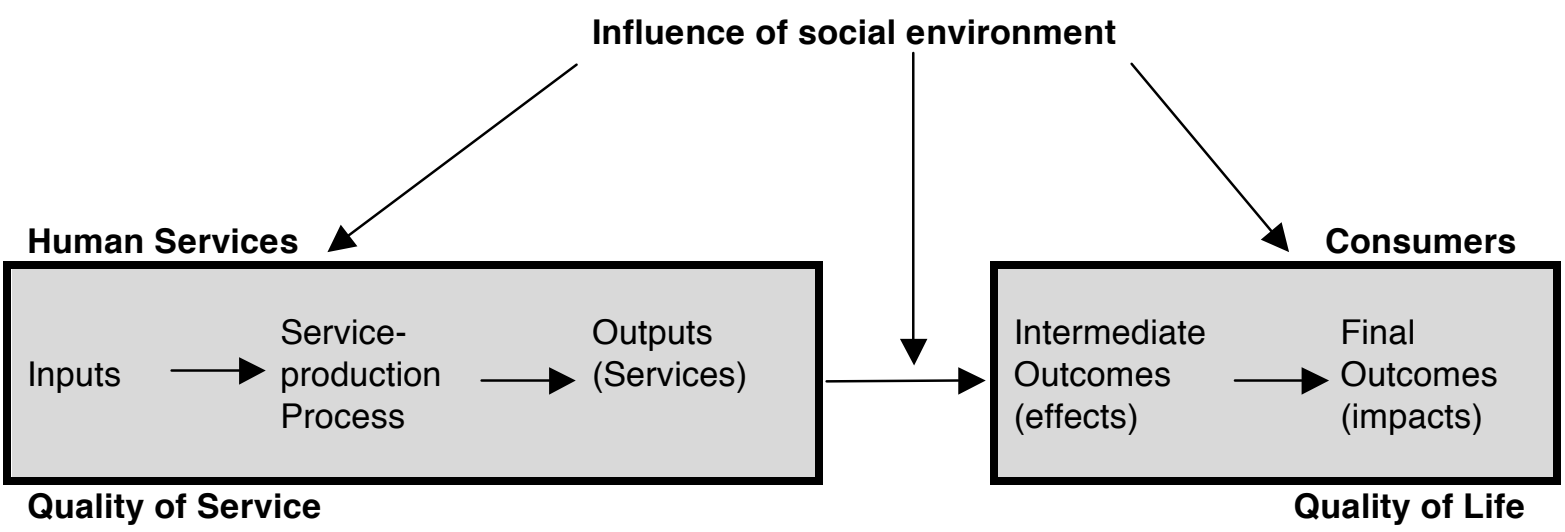

Figure 1 shows that a comprehensive judgement of quality in social-work practice must consider both what is going on inside the agency or organization (i.e., quality of service) and the effects of the services on a client's life-situation (i.e., quality of life). Moreover, the figure demonstrates that the social environment always affects an agency's interventions. For example, this latter aspect could refer to the client's life-situation in general or to circumstances in the local community. In the figure there is also a distinction between 'outputs' and 'outcomes', where the former is connected to quality of services and the latter to quality of life. The concept of 'outputs' refers to an agency's or organization's performances, in the form of, for example, the number of decisions made in relation to a certain type of errand, the number of performed therapeutic sessions or the number of hot meals that were distributed to elderly people.

The concept of outcomes denotes the effects of such interventions in the clients' lives, that is, improvements in the life-situation of clients. The results in respect of quality of life can also be measured at certain points in time, partly as intermediate outcomes (in the short run), and partly as final outcomes (in the long run). Figure 1 also indicates a qualitative distinction involving outcomes. A certain intervention can lead to a person to refrain from drugs ('effect'), which can, in turn, lead to other improvements in that person's quality of life ('impact').

Besides the temporal dimension, the results also have dimensions of surface and depth, which Osborne's model does not account for. We have previously pointed out that the question of results in social work is extraordinarily complicated to conceptualize and study (cf. Blom \& Morén, 2007, 2010). We argue that the results of social work are partly characterized by surface aspects (e.g., the freedom from drugs and an adaptation to demands of the surrounding environment), and partly by depth aspects (e.g., a reappraisal of one's previous way of living and relation to other people). There is also a temporal dimension, which means that we can talk about results as a process. This highlights, as an aspect of the complexity of the task, the fact that change in social-work practice cannot be unambiguously established at a certain point in time; it is dynamic and changeable. 
Osborne (1992) also argues that quality of life can be divided into welfare and well-being. ${ }^{2}$ In general terms welfare means 'individual satisfaction of needs' (which roughly corresponds to Abraham Maslow's hierarchy of needs), and well-being means 'individual experiences of life' (Osborne, 1992, p. 444). These types of quality of life can, according to Osborne, be valued from objective as well as subjective criteria. Consequently, there are four different aspects of life quality, as table 2 demonstrates.

Table 2. Four different aspects of quality of life. (Adapted from Osborne, 1992:444).

\begin{tabular}{lll}
\hline Type of life quality & \multicolumn{1}{c}{ Objective } & \multicolumn{1}{c}{ Criteria } \\
\hline $\begin{array}{l}\text { Welfare } \\
\text { (individual satisfaction } \\
\text { of needs) }\end{array}$ & $\begin{array}{l}\text { E.g., socio-economic status, health } \\
\text { condition }\end{array}$ & $\begin{array}{l}\text { E.g., oral or written accounts } \\
\text { (e.g., 'I get the help I need' or } \\
\text { 'I never have money for a vacation') }\end{array}$ \\
$\begin{array}{l}\text { Well-being } \\
\text { (individual experience } \\
\text { of life) }\end{array}$ & $\begin{array}{l}\text { E.g., psychological tests or } \\
\text { instruments }\end{array}$ & $\begin{array}{l}\text { E.g., oral or written accounts } \\
\text { (e.g., 'I felt like a king' or } \\
\text { 'The future looks dark because...') }\end{array}$ \\
\hline
\end{tabular}

In short, this model illustrates that quality of life relates to two basic dimensions: welfare and well-being. These dimensions can be measured with objective as well as subjective criteria. A cross-tabulation of dimensions and criteria yields four different aspects of quality that can be used as a guide when conducting empirical studies.

\section{The importance of distinguishing quality of service from quality of life}

Distinguishing quality of service from quality of life is important in several respects. For example, it illustrates the general difficulty in equating good quality of service (e.g., interventions in social-work practice) with good quality of life because appropriate interventions do not necessarily result in a good or better quality of life for the client. An almost 'classical' example would be the Swedish 'Uppsala model', which was developed during the 1990s; this was an programme of activation for persons applying for financial subsidies from the social services. In brief, this programme established a higher quality of service in some respects; all clients were treated quickly, equally, and to the same

\footnotetext{
2 The concepts of welfare and well-being are somewhat difficult to define because the literature varies a good deal in this regard (see, for example, Baldwin, Godfrey \& Propper, 1992; Dickinson, 2008; Jordan 2008). In this article we have chosen to use Osborne's definition since it explicitly relates these terms to the evaluation of quality in human services. Moreover, many other definitions of welfare and well-being are quite similar to Osborne's.
} 
standard. It was assumed that the quality of life (in respect of welfare) improved for those clients who received monetary benefits. However, evaluative studies of the programme showed that several clients were not helped, and that quality of life (as subjectively experienced well-being) for many clients deteriorated as a consequence of the programme (Karlsson, 1995; Milton, 2006). Many clients felt offended, sad, and despondent.

On the other hand, there are other examples where the interventions in some respects were inferior, but the results for the clients were positive. For instance, in one of our studies (Blom \& Morén, 2007), we noted that personnel at a treatment clinic treated a young woman with drug problems in a deeply offending manner. However, thanks to persons in the young woman's social network (e.g., other professionals), she was able to transform her negative experiences into something positive. She turned the feelings of being offended into anger and that made her more motivated to quit using drugs. This effect can be a consequence of the fact that social work always takes place in a context where social workers' interventions interact with other and often unpredictable factors in the clients' surroundings (Blom \& Morén, 2010). The conclusion is that it is not sufficient to focus merely on the quality of service, even if it is a highly important aspect of quality in social work.

\section{The problem with regarding all sorts of quality of results as quality of life for clients}

Another problem that arises when evaluating social-work practice is that it is uncertain how clients' quality of life relates to other types of quality of results. This problem can take one of two different expressions: 1) all types of quality of results are considered to be important for the clients, and 2) a certain type of quality of results is regarded as more important than others.

Let us start with the first expression of this problem, that all types of quality of results are considered to be important for the clients. As we see it, not all indicators of quality of results are adequate for evaluating clients' quality of life. Changes which are positive for politicians, managers, social workers, other professionals, taxpayers and others do not always have a positive influence on clients' quality of life. Sometimes several assumptions about the quality of results obviously coincide, so that most stakeholders can agree that a certain measure mirrors a positive change. An example would be the survival of a drug abuser as a result of the social services' interventions.

But unanimous opinions about results are not always the case in social-work practice. Imagine, by way of example, evaluations that concentrate on compulsory care of people with psychiatric problems, drug addicts or youth with detrimental behaviour. These are examples of rather drastic interventions that from the society's perspective can be highly desirable. These types of interventions can be carried out with a high quality of service, can be costeffective, and can lead to reduced levels of burglaries, gang violence, persons with mental problems in the streets and so on. In this respect the quality of results would be high - but mainly for others than the clients directly affected. For the clients such interventions can mean that their quality of life declines, and some of them will probably receive rather unwanted interventions. This, in turn, could make them feel worse - at least in the short term. Our point is that 
all sorts of quality of results are not important from a client's perspective and cannot routinely be ranked as being equal to quality of life.

The other expression of the above-mentioned problem is the claim that $a$ certain type of quality of results in social work is more important than other types. For example, in the present discussion on social work and evaluation there are many who argue in favour of evidence-based practice (EBP). It is said to be the most ethical to use interventions or methods that have been proven in previous studies to produce positive client effects, that is, results in the client's life-situation (above all, as changed behaviour). By way of ethical arguments advocates of EBP have thus asserted that client effect is a superior dimension of the quality of results. Obviously, it is hard to argue against the claim that results in the form of client effects are important in social-work practice. Nevertheless, it can be questioned if client effects are always the most relevant dimension of quality of results. We can also ask the extent to which client effects are comparable to changes in quality of life. In our opinion it is problematic to adopt an a priori view of client effects as being equal to clients' quality of life. From time to time - as in the example above - clients do not want help and therefore experience a reduced quality of life as a result of the interventions. Moreover, measures that are used for evaluating client effects sometimes do not reflect clients' quality of life accurately.

Currently it is quite usual that client effects are measured through standardized instruments that concentrate on behavioural change (e.g., changes in use of alcohol and narcotics). Often these instruments are very useful for social workers and researchers, but the diminished use of drugs, for instance, does not necessarily mean an increased quality of life for the client. The addictive behaviour can persist but in other forms, like a gambling addiction or eating disorders, which make the client feel terrible. In sum, we argue that clients can still have problems and feel bad after (or as a consequence of) a programme, in spite of the fact that quality in relation to client effects are good. It is consequently problematic to claim that a certain type of quality of results is more important than other types. ${ }^{3}$

We do not claim that social workers always must pay most of their attention to their clients' conceptions of the results. Sometimes, for example, other persons' need of protection and stability are more important than a client's desire to live his life as he or she wants. What we emphasize is that all sorts of results in social-work practice do not necessarily mean an increased quality of life for the clients. Evaluators and commissioners should therefore reflect on this distinction before conducting an evaluation in social work. Now, let us turn to the stakeholders' perspective and the importance of balancing different interests when evaluating quality in social-work practice.

\section{Quality from the stakeholders' perspectives}

In public organizations, that is, the kind of arena where much social work is carried out, the issue of quality can be viewed from different perspectives. If we take the Personal Social Services (PSS) as a typical example, there are at

${ }^{3}$ It is not only client effects (e.g., less drinking, less criminality, more days in work) that are sometimes regarded as the foremost quality of results; efficiency ('value for money') is also often viewed as a superior type of quality of results. 
least four different stakeholders that an evaluator has to consider and relate to: politicians, administrative management, social workers, and clients. As mentioned earlier, our point of departure is that the evaluator is often able to influence how the evaluation is ultimately designed and carried out.

In contrast to the business sector, it is not an easy matter to decide who the 'customer' is in social work. If there are several stakeholders, the evaluator has to decide whether all of them are equally important or whether one or more of them are more important than the others. This decision is necessary due to limitations of time and money. The involvement of many categories of stakeholders often means that the evaluation takes more time and costs more. A number of researchers have argued for the merits of including several stakeholders in the evaluation (e.g., Greene, 1988; Weiss, 1983), and in principle we can sympathize with this idea. However, our experiences as evaluators of small- and middle-sized agencies and organizations strongly suggest that there are seldom enough resources to include more than two or three categories of stakeholders. Consequently the evaluator is often forced to make a choice.

For example, is the perspective of the politician most important because social work is part of a representative democracy where the people elect the politicians? Or is the clients' perspective most important because they are directly affected by the interventions? It is also possible that the social workers' perspectives are most important because they deal with many clients and possess knowledge and a more holistic view of the organization and the helping processes. The issue of balancing the different interests of the stakeholders in order to make a judgement on quality is truly a delicate matter in social work.

On the basis of our experiences, we believe that this act of balancing between different stakeholders can be handled in different ways when evaluating social-work practice. For analytical reasons we here present them as three distinct strategies:

1) The inclusion of representatives of all categories of stakeholders: When this is accomplished, the evaluator could a) use the dominant opinion among them as the basis for conclusions, or b) only describe different stakeholders' opinions without making concluding judgements. It is up to the reader of the evaluative report to decide how different perspectives should be balanced;

2) The use of theory or a normative basis: Here the evaluator turns to some text that in principle states how something should be or should work in order to decide which category of stakeholders are most relevant to include in a specific evaluation. Texts on political theory, theory of professions, ethical principles, or a law could provide this basis;

3) The involvement of only intended users: This strategy looks only to persons who want and can make a difference by using the results of the evaluation, like strategically positioned bureaucrats within an organization. This strategy risks excluding clients' participation, since they normally have limited possibilities to change a programme or an organization directly. 
In practice it is sometimes possible (or necessary) to combine these strategies. By way of example, one of us conducted an evaluation where almost all possible stakeholders were included (Blom, 1996). The commissioner wanted to know how the presence of a social worker at a local health-care unit was experienced by the management, physicians, nurses, physiotherapists, clients, and other organizations that cooperated with the social worker. The intended user of the results (the head of the unit) participated in the evaluation, and theory about inter-organizational cooperation was used to decide which external stakeholders were most relevant in this case. The commissioner regarded the client's perspective as being tremendously important and nearly self-evident. Thus several clients both women and men, with different problems - were interviewed about their experiences.

Even if the client often is considered to be the most important stakeholder, it is still not self-evident to assume that the client's perspective is always the most important when evaluating social work. Many clients do not (at least initially) want interventions from the services or any contact with social workers. One example of this reluctance would be parents whose children are taken into custody against their will or persons who are involuntarily treated for drug abuse. As the concept of customer presumes that there is a market in which there is information about different alternatives and choices of products and services (Le Grand \& Bartlett, 1993), it appears inappropriate to view clients as customers at all. However, many consumer investigations in social work do base evaluations on this market-orientated view.

The groups of stakeholders mentioned above are not the only stakeholders that need to be taken into consideration, and there can be other aspects of quality as well. In the next section we shall discuss this point in relation to basic elements of quality of services.

\section{Judging quality of services with regard to different stakeholders' interests}

The quality of services can be divided into three basic elements: structure quality, process quality and results quality. In this article, these concepts are defined in accordance with a Swedish Government Report (Swedish Ministry of Finance, SOU 2005:110, p. 61):

Structural quality concerns resources, staffing and levels of competence, localities, group sizes, and so on.

Processual quality covers the implementation of the services, for instance, work modes, attitudes towards the clients, content, and working climate.

Quality of results denotes the goals and results of an organization, both what is actually obtained and whether this is in accordance with official goals. An example would be whether a social-services agency obtains the goal of offering refugees a certain level of living standard (e.g., a place to live, food, clothes etc.) and a certain level of quality of life (e.g., reduction of anxiety and meaningful daily activities). 
As mentioned in the foregoing section, quality in social work can be viewed from several perspectives. The complexity of the concept of quality becomes even more apparent when the three elements of quality are placed in a table with eight possible categories of stakeholders that have different demands concerning quality. The result is table 3 below, with 24 different fields concerning different aspects of quality, all in varying degrees relevant to evaluations of social-work practice. Owing to a lack of space, each cell in the table contains only one of the areas that each category of stakeholders can lay claim to. It should also be noted that several of the categories of stakeholders could lay claim to the same areas. By way of example, it is not only the clients who are interested in results concerning quality of life, but several categories of stakeholders (e.g., relatives).

Table 3. Examples of aspects of quality from different stakeholders' perspectives.

\begin{tabular}{llll}
\hline & $\begin{array}{l}\text { Structural } \\
\text { quality }\end{array}$ & $\begin{array}{l}\text { Processual } \\
\text { quality }\end{array}$ & $\begin{array}{l}\text { Quality of } \\
\text { results }\end{array}$ \\
\hline Clients & Rooms & Treatment & Quality of results \\
Staff & $\begin{array}{l}\text { Number of } \\
\text { colleagues }\end{array}$ & Influence & Quality of service \\
Managers & Group sizes & Working climate & Output \\
$\begin{array}{l}\text { Politicians } \\
\text { Relatives }\end{array}$ & Economy & Methods & Efficiency \\
Other caregivers & Organization & Carrying through & Productivity \\
$\begin{array}{l}\text { Other } \\
\text { organizations }\end{array}$ & Competition & Interventions & Effects \\
The public & Supply & Justice & Ethics \\
\hline
\end{tabular}

It is seldom possible to include all the dimensions of quality in evaluations because the evaluator has to concentrate on a smaller number of stakeholders and fewer aspects of quality. As mentioned above, it is often a question about the evaluator's resources. Table 4 presents an example of elements of quality that are defined in relation to two groups of stakeholders at a care-giving institution within the elderly care: the clients and the staff.

Table 4. Different aspects of quality at a care-giving institution within elderly care.

Structural quality Processual Quality of




\begin{tabular}{|c|c|c|c|}
\hline & & quality & results \\
\hline Clients & $\begin{array}{l}\text { Rooms } \\
\text { Fees } \\
\text { Staff's competence } \\
\text { Care/living conditions } \\
\text { etc. }\end{array}$ & $\begin{array}{l}\text { Continuity } \\
\text { Trust } \\
\text { Treatment } \\
\text { Security } \\
\text { Time to use etc. }\end{array}$ & $\begin{array}{l}\text { The elderly's } \\
\text { satisfaction with } \\
\text { the results } \\
\text { (Quality of life) }\end{array}$ \\
\hline Staff & $\begin{array}{l}\text { Equipment and } \\
\text { aesthetics } \\
\text { Working hours and } \\
\text { status } \\
\text { Colleagues } \\
\text { Management/support } \\
\text { Working conditions } \\
\text { etc. }\end{array}$ & $\begin{array}{l}\text { Stress } \\
\text { Responsibility } \\
\text { and Influence } \\
\text { Work content } \\
\text { Physical strain } \\
\text { Contacts with the } \\
\text { elderly and the } \\
\text { relatives etc. }\end{array}$ & $\begin{array}{l}\text { The staff's } \\
\text { experiences of } \\
\text { the care work } \\
\text { (Quality of } \\
\text { service) }\end{array}$ \\
\hline
\end{tabular}

The example in table 4 illuminates a number of central aspects that can be important for the evaluator to consider when evaluating quality at an institution within elderly care. It is apparent that even if the example is less complex in comparison to table 3 , it can still be difficult to include every aspect in an evaluation. In reality an evaluator (via a dialogue with the those who commissioned the evaluation) must often narrow an evaluation down by choosing one category of stakeholders (e.g., the elderly) or only one element of quality (e.g., processual quality). Another alternative is only to evaluate one aspect of the processual quality (e.g., old people's experiences of the treatment).

More generally, this discussion has aimed to illustrate that the concept of quality consists of several aspects, and that it is seldom possible to include all of them in an evaluation. Consequently, it is important to clarify the aspects that are most relevant, and as a result one focuses on certain aspects and disregards others. One way of doing this is, as discussed above, to use theories about quality in the kind of agency or organization one plans to evaluate.

\section{Concluding discussion}

This article has discussed quality in relation to the evaluation of social-work practice. As it has been shown, quality in social-work practice is a very multifaceted phenomenon and the concept can be approached from different perspectives and with different foci. Owing to the complex character of the practice, interventions cannot be fully standardized and the effects of the interventions in peoples' lives are not always evident.

Regarding the evaluation of social-work practice, one conclusion is that it is crucial to be aware of and to consider the distinction between quality of service and quality of life. Referring back to Dahler-Larsen (2008), the reader will recall that this distinction will make it easier to define desirable standards of different aspects of the services: structural quality, processual quality, and quality of results. It will also help the evaluator to make better and more 
nuanced descriptions of the effects in clients' lives and, not least, to infer the way these effects stem from the content of the interventions.

With respect to effects, another conclusion is that increased or at least maintained quality of life on behalf of the clients is an important but often disregarded aspect of outcome. Currently there is a focus on measuring client effects in terms of drug use, criminality, school attendance, bullying, days at work, aggressiveness, and more. We have already mentioned the predominant EBP movement as a promoter of standardized instruments that concentrate on behavioural change. Though these changes are obviously important, we cannot routinely and a priori regard positive behavioural changes as an indication of increased quality of life for a client.

A third conclusion concerning judgement of quality of social work is that such judgements are inevitably and internally linked to and dependent on different stakeholders' perspectives. This not only goes for the judgement of quality of life, but for all kinds of outcomes in social work. Consequently, it is important in any evaluation to be clear about and to describe in the report explicitly from whose perspective observed outcomes are viewed and assessed.

In this article we have discussed the issue of judging quality in social-work practice mainly with regard to the public sector. However, the same general aspects of human-services quality will probably be valid for the private and voluntary sectors (e.g., with the social work carried out by the Salvation Army). Our general conclusion is that in every evaluation of social-work practice, regardless of branch or direction, it is important to be explicitly aware of which aspects of quality are being considered and investigated and which are not.

We hope that this article can be useful for those who initiate, conduct, and utilize evaluations of social work. Furthermore, we hope that it can contribute to an increased consciousness about the importance of studying quality of life when evaluating social-work practice. In particular, clients' subjective experiences of welfare and well-being deserve greater attention. This is important partly due to ethical reasons (since social work primarily exists for clients), and partly due to methodological reasons (since the clients' subjective experiences form a source of fundamental knowledge for those who carry out and are responsible for social work). Disregarding this perspective will incur a risk that the overall aim of social work - which focuses on either the maintenance of a good quality of life or the improvement of an insufficient quality of life for socially vulnerable people - will be obscured.

\section{Acknowledgements}

We would like to acknowledge the work done by the copy editor and the two anonymous referees.

\section{References}

Baldwin, S., Godfrey, C., \& Propper, C. (Eds.) (1992). Quality of life: Perspectives and polices. New York: Routledge. 
Blom, B. (1996). Kurator i primärvård. Utvärdering av kuratorsverksamheten vid Skelleftehamns vårdcentral [Welfare officers in primary care: evaluation of welfare-officer activities at Skelleftehamn's health centre]. (Paper no. 6). Umeå: Umeå Universitet, Institutionen för socialt arbete.

Blom, B. (1998). Marknadsorientering av socialtjänstens individ- och familjeomsorg. Om villkor, processer och konsekvenser, Doktorsavhandling [Market orientation of the social services' care of individuals and families: on conditions, processes, and consequences (doctoral thesis)]. Inst. för socialt arbete, Umeå universitet.

Blom, B. \& Morén, S. (2007). Insatser och resultat i socialt arbete [Interventions and results in social work]. Lund: Studentlitteratur.

Blom, B. \& Morén, S. (2010). Explaining social work practice: the CAIMeR-theory. Journal of Social Work, 10(1), 98-119.

Blom, B. \& Morén, S. (2011). Analysis of generative mechanisms. Journal of Critical Realism.10(1), 60-79.

Dahler-Larsen, P. (2008). Kvalitetens beskaffenhed [The nature of quality]. Odense: Syddansk universitetsforlag.

Dickinson, H. (2008). Evaluation outcomes in health and social care. Bristol: The Policy press.

Frank, J. D. \& Frank, J. B. (1991). Persuasion and Healing: A Comparative Study of Psychotherapy. Baltimore: The John Hopkins University Press.

Greene, J. G. (1988). Stakeholder Participation and Utilization in Program Evaluation. Evaluation Review, 12(2), 91-116.

Howe, D. (1987). An Introduction to Social Work Theory. Aldershot: Ashgate.

Jordan, B. (2008). Welfare and well-being: Social value in public policy. Bristol: The Policy press.

Karlsson, U. (1995). Uppsalamodellen - ett nygammalt arbetssätt inom socialt arbete [The Uppsala Model: a new-old way of working in social work]. Nordisk Sosialt Arbeid, (4), 243-257.

Kazi, M.A.F. (2003). Realist evaluation in practice: health and social work. London: Sage.

Knei-Paz, C. (2009). The Central Role of the Therapeutic Bond in a Social Agency Setting: Clients' and Social Workers' Perceptions. Journal of Social Work, 9(2), 178-198.

Le Grand, J., \& Bartlett, W. (Eds.). (1993). Quasi-markets and social policy. London: Macmillian.

Miller, W. R. \& Rollnick, S. (1991). Motivational Interviewing. Preparing People to Change Addictive Behaviour, New York, The Guilford Press.

Milton, P. (2006). Arbete i stället för bidrag? Om aktiveringskraven i socialtjänsten och effekten för de arbetslösa bidragstagarna [Work instead of benefits? On the demand for activation in the social services and the effect on the unemployed receivers of benefits]. Akademisk avhandling, Uppsala universitet.

Morén, S. \& Blom, B. (2003). Explaining human change: On generative mechanisms in social work practice. Journal for Critical Realism, 2(1), 37-61. 
Nordlander, L. \& Blom, B. (2000). Underlag för förändring - kvalitetsutveckling av socialtjänstens individ- och familjeomsorg (IFO) [Basis for change: the development of quality of individual and familial care in the social services (IFO)]. Skriftserie 3/2000. Utvecklings- och fältforskningsenheten (UFFE) vid Umeå socialtjänst.

Osborne, S. P. (1992). The quality dimension: Evaluating quality of service and quality of life in human services. British Journal of Social Work, 22(4), 437-453.

Pawson, R., \& Tilley, N. (1997). Realistic evaluation. Thousand Oaks: Sage.

Roberts, A. R., \& Yeager, K. R. (Eds.). (2004). Evidence-based practice manual. Oxford: Oxford University Press.

Swedish Ministry of Finance. (2005). Jämförelsevis - Styrning och uppföljning med nyckeltal i kommuner och landsting: betänkande av Rådet för kommunala analyser och jämförelser [Comparatively: steering and follow-up of key numbers in municipalities and county councils: reflections by the Council for municipal analyses and comparisons] (SOU 2005:110). Stockholm: Fritzes.

Stake, R. E. \& Schwandt, T. A. (2006). On discerning quality in evaluation. In I. F. Shaw, J. C. Greene \& M. M. Mark (Eds.) The Sage Handbook of Evaluation. pp. 404-418. London: Sage.

Sundström, E. (2009). Tjänster och relaterade begrepp - Innebörd och implikationer för policy [Services and related concepts: meanings and implications for policy]. VINNOVA Rapport VR 2009:08.

Vedung, E. (2009). Utvärdering $i$ politik och förvaltning [Evaluation in politics and administration]. Lund: Studentlitteratur.

Weiss, C. (1983). The stakeholder approach to evaluation: Origins and promise. New Directions for Evaluation. Vol. 1983, (17), 3-14. 